\title{
Forum
}

\section{Correct framing of biodiversity offsets and conservation: a response to Apostolopoulou \& Adams}

\author{
Amrei von Hase and Kerry ten Kate
}

$\mathrm{W}$ e read with great interest the opinions of Apostolopoulou \& Adams (2015) on biodiversity offsetting. We agree with the authors that offsetting has more profound implications than a technical approach to the subject would suggest. Our experience with developments on the mitigation of impacts on biodiversity in government policy, financial lenders' safeguards and corporate practice is that the political, economic, social and financial implications weigh just as heavily in decision-makers' minds as the technical ones that Apostolopoulou \& Adams raise (IFC, 2012; BBOP, 2012b; ten Kate \& Crowe, 2014; IUCN, 2016; Maron et al., 2016b). The governments, companies and communities working with scientists on the mitigation hierarchy regard biodiversity offsets as one of many tools available not only for conservation but also for risk management, social and economic engagement and benefit-sharing, landuse and landscape-level planning, and sustainable development (IFC, 2012; CSBI, 2015).

Correctly framed, biodiversity offsetting is just the last step in a continuum of measures in the mitigation hierarchy (BBOP, 2013; IUCN, 2016). Although biodiversity offsets may be regarded as a conservation tool (in that they are defined as additional and measurable conservation outcomes; $\mathrm{BBOP}, 2 \mathrm{O} 2 \mathrm{~b}$ ), their specific purpose is to address residual impacts on biodiversity caused by development after alternatives have been considered and rigorous avoidance, minimization and restoration measures undertaken. Consequently, biodiversity offsets can at best only ever remediate losses, and are therefore widely regarded as just one of many approaches to conservation that are needed (IUCN, 2016). The more traditional approaches of establishing protected areas and conservation activities outside formal protected areas remain the dominant forms of conservation. The full suite of conservation activities continue in the context of national planning, supporting international and national conservation strategies in situations unrelated to making good residual losses of biodiversity caused by specific footprints. This broader approach to conservation (and thus the modest role of biodiversity offsets within it) appears to us to be widely accepted (European

Amrei von Hase (Corresponding author) and Kerry ten Kate Forest Trends Association, 1203 19th Street, NW, 4th Floor, Washington, DC 20036, USA E-mail avonhase@forest-trends.org

Received 16 August 2016. Accepted 5 September 2016.

First published online 9 November 2016.
Commission, 2014; IUCN, 2016) and we strongly support the transparent accounting of these various conservation measures and their outcomes (e.g. Maron et al., 2016a). We therefore do not recognize from our own experience the suggestion of Apostolopoulou \& Adams that conservation as a whole is 'reframed' by biodiversity offsets. This is especially the case if biodiversity offsets are regarded in their proper context.

Apostolopoulou \& Adams argue that offsetting is presented as a technical issue, thus depoliticizing biodiversity loss as a result of development, and that this 'forecloses' the opportunity to challenge environmental destruction, leaving continued biodiversity loss as the only alternative (although alternative to what is not quite clear). We would agree that if offsets were regarded as merely technical in nature, this would be dangerous. It is therefore encouraging that, to the contrary, there appears to be significant policy and political discussion on the topic (European Commission, 2014; Defra, 2016).

Previously, biodiversity offsets have too often been divorced from their proper context in the mitigation hierarchy and portrayed as an option for all circumstances (e.g. BBC News, 2014), whereas there are plenty of situations in which offsetting residual impacts is impossible or unfeasible (BBOP, 2012a; Pilgrim et al., 2013). Biodiversity offsets have also often been described too generally, without clarity on baselines and reference scenarios, exchange rules and metrics. Individual biodiversity offsets and national systems including them have rarely been conceived to high standards (or have taken many years to approach such standards), and have been inadequately monitored, evaluated and enforced (ten Kate \& Crowe, 2014). Time, capacity and political will are needed to design and implement effective systems for mitigation of impacts on biodiversity, and these have been lacking in most settings where biodiversity offsetting has been tried to date. The results so far have, more often than not, been disappointing (e.g. NRC, 2001). The jury is out as to whether governments and companies can apply the necessary high standards (e.g. BBOP, 2012b) to realize the potential environmental, social and economic benefits that are increasingly recognized by the international community. We agree with Apostolopoulou \& Adams that this is far more an issue of political will than it is one of handling technical challenges. However, we do not agree with their depiction of the problem.

Apostolopoulou \& Adams believe that offsetting reframes nature in terms of isolated biodiversity units that 
can be simply defined, measured and exchanged across time and space to achieve equivalence between ecological losses and gains, and that it reframes biodiversity as lacking locational specificity, ignoring broader dimensions of place and deepening a nature-culture and nature-society divide. Firstly, rather than framing biodiversity in terms of isolated units, best practice approaches to the mitigation of impacts on biodiversity seek to review the overall condition of ecosystems, including key ecological functions and processes, and to select metrics that offer practical but good biodiversity surrogates and proxies. This is done with a view to achieving equivalence between ecological losses and gains. This also requires assessment relative to plausible and defensible reference scenarios or counterfactuals (e.g. Bull et al., 2014; Gordon et al., 2015) and realism in terms of the feasibility of restoration and/or activities to avert loss of biodiversity (Brownlie \& Botha, 2009; Maron et al., 2012). Such approaches are not 'simply defined, measured and exchanged', but practical approaches are essential to limit complexity and ensure a workable outcome. Given its complexity, finding acceptable and appropriate ways to represent biodiversity is an acknowledged and well-known challenge in conservation practice more generally, as it is in mitigation measures, including biodiversity offsetting. Similarly, predicting and measuring conservation benefit relative to reference scenarios, which usually need to rely on a number of assumptions about future states of nature, are also acknowledged as very important for conservation outcomes more broadly (McDonald-Madden et al., 2009; Maron et al., 2013).

Secondly, we do not agree that best practice offsetting strips biodiversity of locational specificity. Instead, it is a core part of the assessment of alternatives and application of the mitigation hierarchy, informing the lengths that must be gone to in specific circumstances to avoid and minimize impacts and to restore affected areas. Crucially, locational specificity also informs the feasibility, nature, scale and location of offsetting activities for any residual losses, which in turn helps define avoidance zones (e.g. Maron et al., 2016b). The issue of place is thus inherent to both policy and practical aspects of planning projects and their mitigation measures, including biodiversity offsets (BBOP, 2012b; IUCN, 2016), and the possibility of exchanges based on global units, as mentioned by Apostolopoulou \& Adams, is in fact rarely raised and would be highly unlikely to meet high standards such as those of the Business and Biodiversity Offsets Programme.

In summary, there is a challenge inherent in finding robust approaches to quantify losses and gains of biodiversity, because this includes intrinsic, socioeconomic and cultural aspects of biodiversity, and measurements need to be possible within reasonable costs and planning periods. This inevitably involves simplification. However, contemporary best practice involves better exchange rules and metrics than were used in the early years of biodiversity offsets.
Importantly, the approach means that residual impacts, which previously were not measured at all and were completely uncompensated, are now addressed. Rather than deepening a nature-culture and nature-society divide, high quality approaches to the mitigation hierarchy, including biodiversity offsets, in fact bridge gaps that were previously ignored, even if they do so imperfectly.

Apostolopoulou \& Adams also state that biodiversity offsetting reframes conservation as an exchange of credits, implying that the value of non-human nature can be set by price, and that it ties conservation to land development and economic growth, foreshadowing and bypassing an oppositional position. In fact, this point misunderstands the approach of biodiversity offsets in two senses. Firstly, conservation as a whole is not being reframed as an exchange of credits. Even in countries with systems of biodiversity offsets, and even in countries where such offset systems offer the creation of credits as one way to generate offsets, action that does not involve credits will probably remain the dominant approach to conservation. This is because conservation is not always a response to negative development impacts but a positive societal choice (inside and outside protected areas, on public and private land, in freshwater and marine systems, by government, companies, communities and NGOs). As stated earlier, biodiversity offsets are just a subset of conservation activities. They only come into play for a specific purpose, which is to respond to the residual losses caused by economic activities with an impact on biodiversity, so that those economic activities do not go uncompensated. It is more accurate to say that conservation credits may be used as one mechanism to deliver biodiversity offsets, which are themselves just one contribution to overall investment in conservation activities.

Secondly, biodiversity offsets, even those implemented through a system of conservation credits, do not imply that the value of non-human nature can be set by price. Biodiversity offsets based on robust metrics are not determined by a notional assessment of the economic value of nature. Rather, they quantify residual losses and additional gains based on measurement of biodiversity and associated costs for remediation. The activities, location, scale and duration of biodiversity offsets are planned at the very least to maintain ecosystems in the same condition as they were in before the impacts to be offset took place. They are determined by measuring changes in the extent and condition of biodiversity, and by working out the associated costs (land, labour, materials, monitoring, etc.) to arrive at the budget needed to deliver no net loss of biodiversity over the long term. This is biodiversity-based and cost-based, rather than placing a value on nature. It is important to note that without taking this approach the price set on biodiversity is zero, as the losses are not quantified and not addressed. The only logical alternative of no impacts may be desirable but is unrealistic in a world of 7.4 billion people 
who consume food, water and medicines, use construction materials and power, and travel.

In conclusion, we argue that the reframing needed in public discourse and journal articles is as follows: there needs to be consideration of biodiversity offsets within the context of the full and rigorously applied mitigation hierarchy, as one of the cornerstones of best practice, and biodiversity offsets need to be viewed realistically and portrayed transparently as part of a more diverse set of strategies for conservation. The risks and opportunities of using biodiversity offsets need to be presented against clear, plausible counterfactual propositions: how can the Aichi targets, Sustainable Development Goals and goals of No Net Loss, Net Gain or Net Positive Impact on biodiversity be achieved without the proper use of biodiversity offsets? What would happen if biodiversity offsets were roundly dismissed as unpalatable and ineffective and any residual impacts were left to accumulate, as they so often are under business as usual or any reasonably foreseeable improvement in practice? We welcome further constructive debate on this subject and hope to see more journal articles that address this issue, as well as public discourse that tackles this complex issue with appropriate depth and builds political will to apply high standards.

\section{Biographical sketches}

This article is based on the authors' research and advisory work for Forest Trends and draws on two principal sources: research on the mitigation hierarchy, policy advice to governments and technical advice to companies, and experience from serving as the Secretariat of the Business and Biodiversity Offsets Programme.

\section{References}

Apostolopoulou, E. \& Adams, W.M. (2015) Biodiversity offsetting and conservation: reframing nature to save it. Oryx, http://dx.doi. org/10.1017/So030605315000782.

BBC News (2014) Destruction of ancient woodland 'highly unlikely'. Http://www.bbc.com/news/uk-25599249 [accessed 24 September 2016].

BBOP (Business and Biodiversity Offsets Programme) (2012a) Resource Paper: Limits to What Can Be Offset. Business and Biodiversity Offsets Programme, Washington, DC, USA. Http:// www.forest-trends.org/documents/files/doc_3128.pdf [accessed 23 September 2016].

BBOP (Business and Biodiversity Offsets Programme) (2012b) Standard on Biodiversity Offsets. Business and Biodiversity Offsets Programme, Washington, DC, USA. Http://www. forest-trends.org/documents/files/doc_3078.pdf [accessed 23 September 2016].

BBOP (Business and Biodiversity Offsets Programme) (2013) To No Net Loss and Beyond: An Overview of the Business and Biodiversity Offsets Programme. Business and Biodiversity Offsets Programme, Washington, DC, USA. Http://www.forest-trends.org/ documents/files/doc_3319.pdf [accessed 23 September 2016].
BRownlie, S. \& BотнA, M. (2009) Biodiversity offsets: adding to the conservation estate, or "no net loss"? Impact Assessment and Project Appraisal, 27, 227-231.

Bull, J.W., Gordon, A., Law, E.A., Suttle, K.B. \&

Milner-Gulland, E.J. (2014) Importance of baseline specification in evaluating conservation interventions and achieving no net loss of biodiversity. Conservation Biology, 28, 799-809.

CSBI (Cross-Sector Biodiversity InItIATIVE) (2015) A Cross-sector Guide for Implementing the Mitigation Hierarchy. Cross Sector Biodiversity Initiative, London, UK. Http://www.csbi.org.uk/toolsand-guidance/mitigation-hierarchy [accessed 25 September 2016].

Defra (Department for Environment, Food \& Rural Affairs) (2016) Consultation Outcome: Biodiversity Offsetting in England: Summary of Responses. Department for Environment, Food \& Rural Affairs, London, UK. Http://www.gov.uk/ government/consultations/biodiversity-offsetting-in-england [accessed 23 September 2016].

European Commission (2014) No Net Loss. Http://ec.europa.eu/ environment/nature/biodiversity/nnl/index_en.htm [accessed 24 September 2016].

Gordon, A., Bull, J.W., Wilcox, C. \& Maron, M. (2015) FORUM: perverse incentives risk undermining biodiversity offset policies. Journal of Applied Ecology, 52, 532-537.

ifC (International Finance Corporation) (2012) Performance Standard 6: Biodiversity Conservation and Sustainable Management of Living Natural Resources. International Finance Corporation, Washington, DC, USA. Http://www.ifc.org/wps/wcm/connect/ bffoa28049a79od6b835faa8c6a8312a/PS6_English_2012.pdf?MOD= AJPERES [accessed 24 September 2016].

IUCN (2016) Draft Biodiversity Offsets Policy. IUCN, Gland, Switzerland. Http://www.iucn.org/theme/ business-and-biodiversity/resources/browse-conservation-issue/ biodiversity-offsets [accessed 24 September 2016].

Maron, M., Hobbs, R., Moilanen, A., Matthews, J.W., Christie, K., GARDNER, T.A. et al. (2012) Are restoration offsets Faustian bargains? Restoration realities in the context of biodiversity offset policies. Biological Conservation, 155, 141-148.

Maron, M., Rhodes, J.R. \& Gibbons, P. (2013) Calculating the benefit of conservation actions. Conservation Letters, 6, 359-367.

Maron, M., Gordon, A., Mackey, B.G., Possingham, H.P. \& WATSON, J.E.M. (2016a) Interactions between biodiversity offsets and protected area commitments: avoiding perverse outcomes. Conservation Letters, in press, http://dx.doi.org/10.1111/conl.12222.

Maron, M., Ives, C.D., Kujala, H., Bull, J.W., Maseyk, F.J.F., Bekessy, S. et al. (2016b) Taming a wicked problem: resolving controversies in biodiversity offsetting. BioScience, in press, http:// dx.doi.org/10.1093/biosci/biw038.

McDonald-Madden, E., Gordon, A., Wintle, B.A., Walker, S., Grantham, H., Carvalho, S. et al. (2009) "True" conservation progress. Science, 323, 43-44.

NRC (National Research Council) (2001) Compensating for Wetland Losses under the Clean Water Act. National Academy Press, Washington, DC. Http://www.nap.edu/catalog/10134/ compensating-for-wetland-losses-under-the-clean-water-act [accessed 20 September 2016].

Pilgrim, J.D., Brownlie, S., Ekstrom, J.M.M., Gardner, T.A., von Hase, A., ten Kate, K. et al. (2013) A process for assessing offsetability of biodiversity impacts. Conservation Letters, 6 , $376-384$.

ten Kate, K. \& Crowe, M.L.A. (2014) Biodiversity Offsets: Policy Options for Governments. An Input Paper for the IUCN Technical Study Group on Biodiversity Offsets. IUCN, Gland, Switzerland. Http:// portals.iucn.org/library/node/44776 [accessed 25 September 2016]. 